\title{
TOWARD A JOINT CATALOGUE OF RECENT SEISMICITY IN WESTERN GREECE: PRELIMINARY RESULTS
}

\author{
Roumelioti Z. ${ }^{1}$, Ganas A. ${ }^{1}$, Sokos E. ${ }^{2}$, Petrou P. ${ }^{1}$, Serpetsidaki A. ${ }^{2}$, and \\ Drakatos G. ${ }^{1}$ \\ ${ }^{1}$ National Observatory of Athens, Institute of Geodynamics, roula@gein.noa.gr, \\ aganas@gein.noa.gr,petrou@gein.noa.gr,g.drakat@gein.noa.gr \\ ${ }^{2}$ University of Patras, Department of Geology, Seismological Laboratory, esokos@upatras.gr, \\ annaserp@geology.upatras.gr
}

\begin{abstract}
Routine catalogue phase data of three Greek permanent seismic networks are merged and jointly used to relocate earthquakes in western Greece. Processed data refer to the time period from 2000 to 2005 and to the geographical area between 35 $42^{\circ} \mathrm{N}$ and $19-22^{\circ} \mathrm{E}$. After the merging procedure, the number of events in the joint catalogue is increased by more than 3000 compared to the individual pre-existing catalogues. Earthquakes are relocated using the Hypoinverse algorithm and several different combinations of $1 D$ velocity models and phase weighting schemes. Among these two tested factors, $S$-phase weights are found to affect the relocation results more drastically. In fact, minimum mean rms, erh and erz values $(0.28 \mathrm{secs}, 3.6 \mathrm{~km}$ and $5.8 \mathrm{~km}$, respectively) are found when $S$-phases are neglected. Relocated epicenters appear more clustered and illuminate well-known, as well as obscure, seismotectonic structures of the area.
\end{abstract}

Key words: relocation, hypoinverse, Ionian.

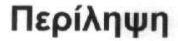

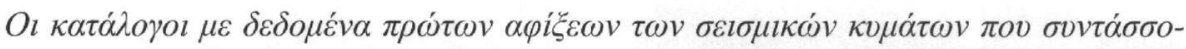

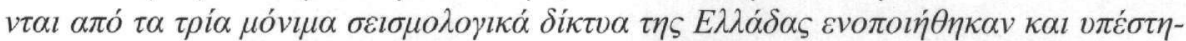

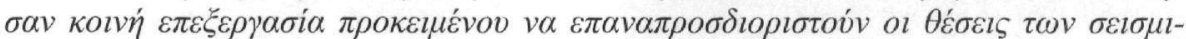

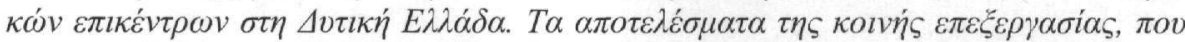

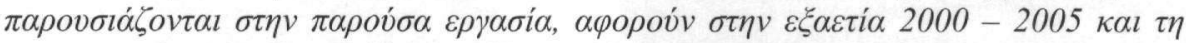

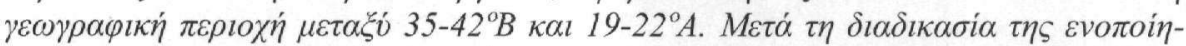

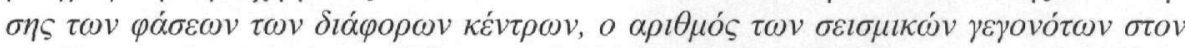

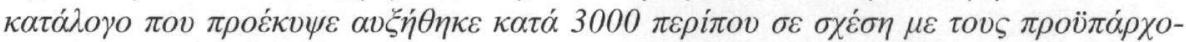

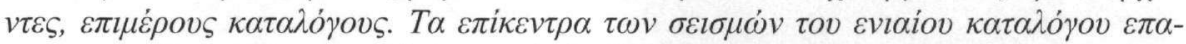

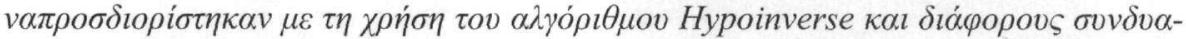

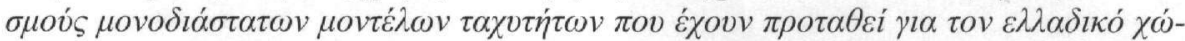

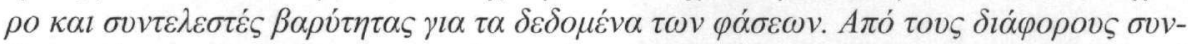

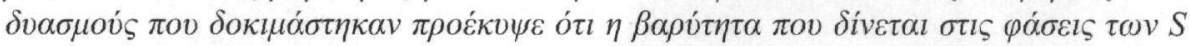

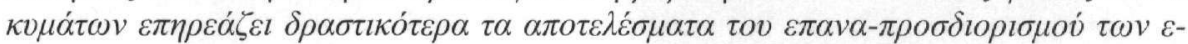

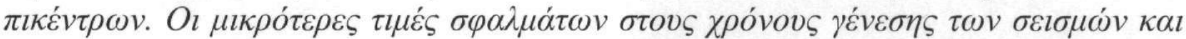

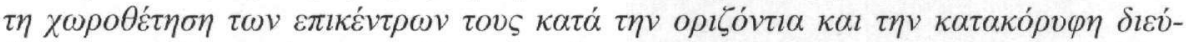

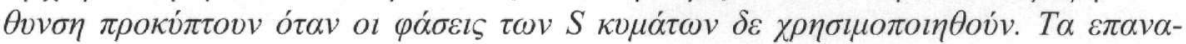




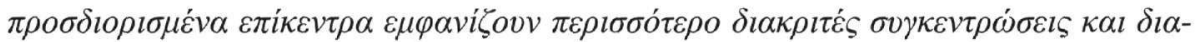

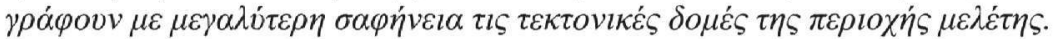

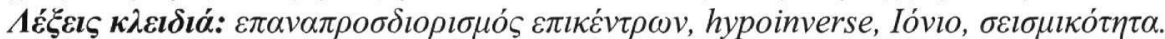

\section{Introduction}

Routine epicentres determinations frequently comprise the basis for detailed scientific work in several fields of seismology, e.g. earthquake prediction, stress transfer studies etc. But how accurate are these epicentres? In Greece, the average uncertainties in the catalogue hypocenter locations are of the order of $12 \mathrm{~km}$ in the horizontal (erh) and $3 \mathrm{~km}$ in the vertical (erz) direction (Skarlatoudis 2002). To our knowledge, this is the only published quantification of catalogue locations uncertainties in Greece and the fact that the horizontal uncertainty appears to be larger than the vertical (usually the reverse is expected) probably reflects the usual depth constraints in routine analysis. In western Greece, these uncertainties are expected to be even larger as the presence of the Adriatic Sea prevents the deployment of seismological stations to the west. As a result of the unilateral station distribution, most earthquakes in this area are practically located outside the permanent networks. Unless ocean bottom seismometers are used, the azimuthal coverage of these earthquakes cannot exceed the $180^{\circ}$.

The aim of the present study is to combine and merge earthquake phase data from different available archives, in order to relocate the seismicity of western Greece. Although the unification of existing earthquake catalogues cannot overcome the problem of the insufficient station coverage of the area, we expect to obtain more accurate source parameters and thus an enhanced picture of the epicentres distribution. Results presented herein are preliminary as they refer only to the spatial distribution of the earthquake foci within the area $35-42^{\circ} \mathrm{N}$ and $19-22^{\circ} \mathrm{E}$ (Fig. 1) and to the time interval 2000-2005. Further processing of older phase data and development of automated procedures for the unification of earthquake magnitudes are future targets of the on-going efforts toward the compilation of a joint seismicity catalogue.

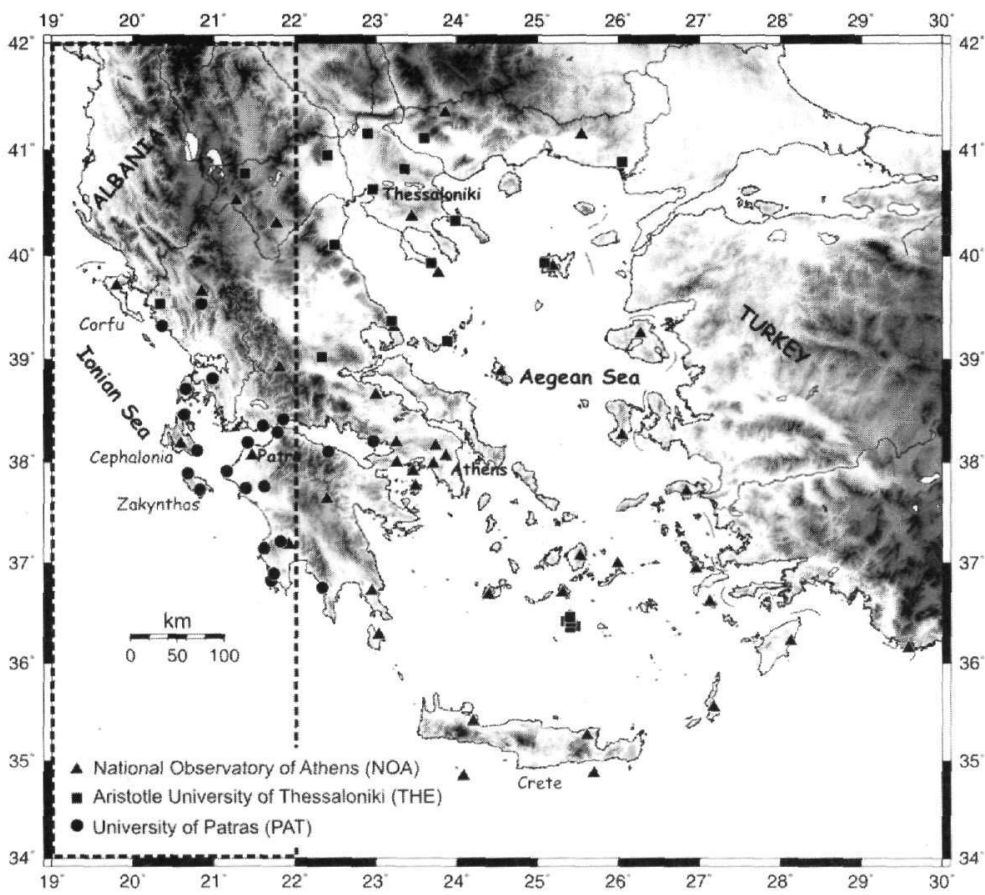

Figure 1 - Locations of stations included in the archives (2000-2005) of the three Greek seismological institutes. Dashed frame outlines the area of study 


\section{Data}

\subsection{Data sources}

Earthquake catalogues for the study area are provided by three different sources: the Institute of Geodynamics of the National Observatory of Athens (NOA, www.gein.noa.gr), the Department of Geophysics of the Aristotle University of Thessaloniki (THE, seismology.geo.auth.gr) and the Seismological Laboratory of the University of Patras (PAT, seismo.geology.upatras.gr). Phase data from these institutes were either requested (from NOA and PAT) or retrieved online (from THE webpage). Figure 1 shows the locations of the stations whose phases are archived by the three seismological centres.

\subsection{Merging the phases of different catalogues}

The most troublesome part of the study was the matching up of events in the available catalogues. Difficulties arose from the different character of the three networks (different station density resulting in catalogues of different completeness), as well as the presence of aftershock/foreshock sequences in the catalogues (in cases of events that occur very close to each other in time, the automatic merging procedure may erroneously merge phases of different events). Another major problem was the inconsistencies in the reporting of event parameters. Although earthquake catalogues are expected to have specific formats, parts of them have been edited and altered manually by the analysts. Such alterations, although small, caused significant problems during the automated phase merging procedure and required numerous manuals checks and corrections of the original archives.

A FORTRAN code was written to scroll the individual bulletins for identification of events with reported locations within the study area. The unification procedure included the following steps: first, the catalogue of NOA, containing the largest number of events, was scrolled and once an event of interest was detected, the routinely calculated origin time was read. Then, the code scrolled the other two catalogues looking for a first phase that is within a certain time window right after the origin time. If such a phase was detected, the following phases, belonging to the same event, were also merged. After comparing all three available catalogues together, the procedure was repeated for only the data of PAT and THE (i.e, searching for events that have been reported by only these two institutes). Finally, "single-network" events, i.e. earthquakes that had been recorded by only one network, were detected and included in the joint catalogue.

Table 1 shows the statistics of the merging of the three earthquake phase data sets. PAT appears to have the most complete catalogue, owing to its denser network throughout most of western Greece. However, during 2000 and 2004, NOA recorded more events. Even THE, which has the smaller number of stations in the area, contributed 318 "single-network" events for the examined time period. Therefore, none of the three catalogues can be considered as a subset of the other.

Table 1 - Statistics of merging the three catalogues

\begin{tabular}{|l|c|c|c|c|c|c|c|}
\hline \multirow{2}{*}{ Institute } & \multicolumn{5}{|c|}{ Number of reported events per year } & \multirow{2}{*}{ Total } \\
\cline { 2 - 8 } & $\mathbf{2 0 0 0}$ & $\mathbf{2 0 0 1}$ & $\mathbf{2 0 0 2}$ & $\mathbf{2 0 0 3}$ & $\mathbf{2 0 0 4}$ & $\mathbf{2 0 0 5}$ & \\
\hline $\begin{array}{l}\text { National Observatory } \\
\text { of Athens (NOA) }\end{array}$ & 899 & 868 & 1171 & 1309 & 960 & 1183 & 6390 \\
\hline $\begin{array}{l}\text { Aristotle University of } \\
\text { Thessaloniki (THE) }\end{array}$ & 316 & 196 & 208 & 415 & 721 & 442 & 2298 \\
\hline $\begin{array}{l}\text { University of Patras } \\
\text { (PAT) }\end{array}$ & 414 & 1290 & 1874 & 1662 & 840 & $\begin{array}{c}\text { Not } \\
\text { available }\end{array}$ & 6080 \\
\hline Joint catalogue & 1075 & 1570 & 2162 & 2056 & 1587 & 1327 & 9777 \\
\hline
\end{tabular}


Overall, the number of events in the joint catalogue is increased by more than 3000 compared to the individual catalogues.

\section{Earthquake relocation with hypoinverse}

Merged phases were subsequently passed to the Hypoinverse code (Klein 2002), which is one of the standard location algorithms that have been distributed by the United States Geological Survey (U.S.G.S.) and the continuation of the most widely used HYPO71 (Lee and Lahr 1972). Hypoinverse was run several times to test different $1 \mathrm{D}$ velocity models and different P- and Sphases weighting schemes.

About $5 \%$ (544) of the events in the joint catalogue had less than four phases and thus failed to fulfil the minimum phase number criterion of Hypoinverse. Consequently, the relocated catalogue contains only 9233 events and if S-phases are not taken into account the number further decreases to 8294 . This means that at least 939 more events are poorly recorded and their locations greatly depend on the S-phase weights.

We tested all three velocity models used by NOA, THE and PAT (Table 2) for routine location of earthquakes in western Greece. Their relative performance in the relocation algorithm was judged based on the mean values of the root mean square (rms), the horizontal (erh) and vertical (erz) errors of the re-determined earthquake locations. Corresponding statistics are included in Table 3. Regarding the mean rms, models of PAT and THE result in almost identical values, while the NOA model value is slightly increased. Differences in mean erh are small, although PAT model appears more appropriate to better constraint foci depths (smallest erz). For this set of calculations, both P-ans S-phase data have been encountered with equal weight.

Table 2 - Velocity models used for routine earthquake location by the three Greek seismological institutes: NOA, THE and PAT

\begin{tabular}{|c|c|c|c|c|c|}
\hline \multicolumn{2}{|c|}{ NOA Model } & \multicolumn{2}{c|}{ THE Model } & \multicolumn{2}{c|}{ PAT Model } \\
\hline $\begin{array}{c}\text { Depth to top of } \\
\text { layer }\end{array}$ & $\begin{array}{c}\mathrm{V}_{\mathrm{P}} \\
(\mathrm{km} / \mathrm{sec})\end{array}$ & $\begin{array}{c}\text { Depth to top of } \\
\text { layer }\end{array}$ & $\begin{array}{c}\mathrm{V}_{\mathrm{P}} \\
(\mathrm{km} / \mathrm{sec})\end{array}$ & $\begin{array}{c}\text { Depth to top of } \\
\text { layer }\end{array}$ & $\begin{array}{c}\mathrm{V}_{\mathrm{P}} \\
(\mathrm{km} / \mathrm{sec})\end{array}$ \\
\hline 0.0 & 5.3 & 0.0 & 6.0 & 0.0 & 5.7 \\
4.0 & 6.0 & 19.0 & 6.6 & 5.0 & 6.0 \\
33.0 & 6.9 & 31.0 & 7.9 & 18.0 & 6.4 \\
45.0 & 7.9 & & & 39.0 & 7.9 \\
85.0 & 8.1 & & & & \\
\hline
\end{tabular}

Table 3 - Statistics on the location accuracy (rms: root mean square, erh: horizontal error, erz: vertical error) using different velocity models

\begin{tabular}{|c|c|c|c|}
\hline \multirow{2}{*}{$\begin{array}{c}\text { Velocity } \\
\text { model }\end{array}$} & \multicolumn{3}{|c|}{ Mean values $\pm \mathbf{1}$ standard deviation } \\
\cline { 2 - 4 } & rms (secs) & erh $(\mathbf{k m})$ & erz $(\mathbf{k m})$ \\
\hline NOA & $0.36 \pm 0.2$ & $4.8 \pm 8.1$ & $8.7 \pm 12.4$ \\
\hline THE & $0.34 \pm 0.2$ & $4.1 \pm 8.2$ & $8.6 \pm 11.3$ \\
\hline PAT & $0.34 \pm 0.2$ & $4.6 \pm 8.6$ & $6.9 \pm 10.0$ \\
\hline
\end{tabular}



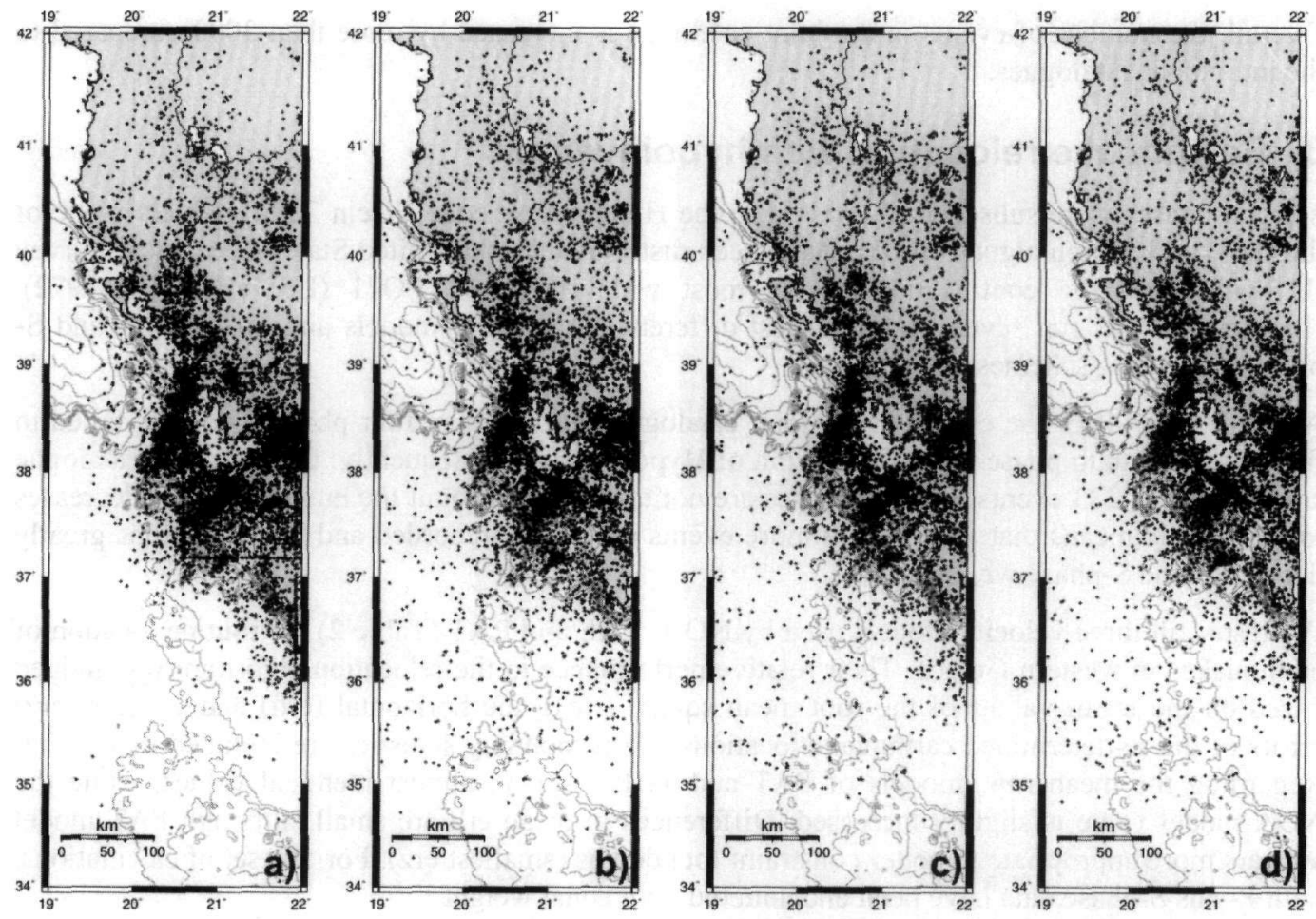

Figure 2-Comparison of epicentre distributions throughout the entire study area a) prior to relocation and as derived with the velocity model used for routine location by b) NOA, c) THE and d) PAT. These results are based on both $P$ - and $S$ - phases, assigned equal weights
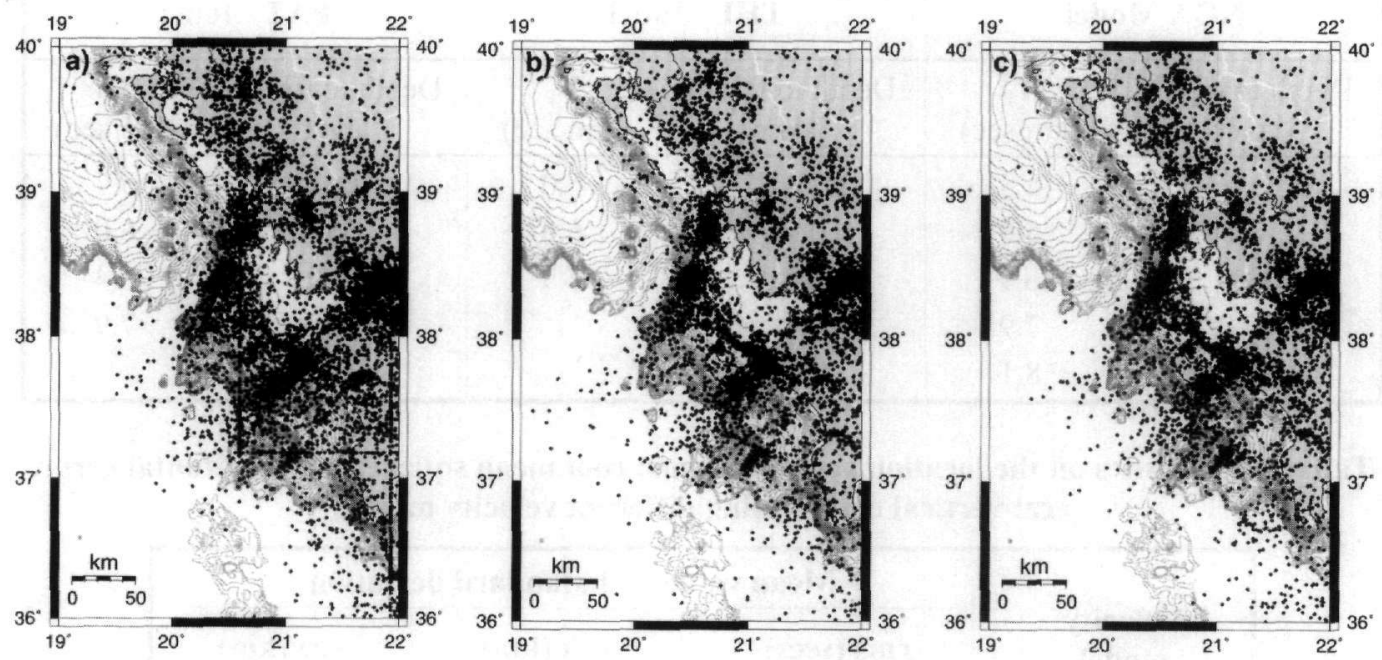

Figure 3 - Comparison of epicentre distributions (central part of the study area) as derived using the PAT velocity model and different S-phases weighting schemes: a) P-and S-phases are equally weighted, b) S-phases are assigned half the weight of $P$-phases and c) $S$-phases are assigned zero weights. The velocity model used for routine location by PAT is adopted in 
The seismicity distributions, as derived based on different velocity models, are compared to the corresponding picture prior to the relocation in Figure 2. Artificial alignments of epicentres in picture $2 \mathrm{a}$ (e.g. along approximately $37.2^{\circ} \mathrm{N}$ ) are missing from all the accompanying pictures where earthquakes appear to be more clustered, although at this scale, one can hardly distinguish any effect of the use of different velocity models. A rather disappointing observation in Figures $2 \mathrm{~b}-\mathrm{d}$ is the appearance of more diffused seismicity, compared to Figure 2a, at the southwestern part of the study area. These epicentres correspond to earthquakes that remain poorly located, even after the use of the joint phase catalogue and are extremely sensitive to the weighting scheme of the S-waves.

This conclusion is better supported by Figure 3, where we plot the relocated epicentres within the central part of the study area as derived using the PAT velocity model and different weights for Sphases. S-phase weights decrease from 1.0 (equal to P-phase weights) in Figure $3 \mathrm{a}$, to 0.5 in Figure $3 \mathrm{~b}$ and 0.0 in Figure $3 \mathrm{c}$ leading to a parallel decrease of the diffused seismicity to the WSW part of the depicted area. Statistics on the corresponding relocation schemes are included in Table 4.

Table 3 - Statistics on the locations accuracy (rms: root mean square, erh: horizontal error, erz: vertical error) using different weights for $\mathrm{S}$-phases

\begin{tabular}{|c|c|c|c|c|}
\hline \multirow{2}{*}{$\begin{array}{c}\text { S-phases } \\
\text { weight }\end{array}$} & \multirow{2}{*}{$\begin{array}{c}\text { Number of relo- } \\
\text { cated events }\end{array}$} & \multicolumn{3}{|c|}{ Mean values $\pm \mathbf{1}$ standard deviation } \\
\cline { 3 - 5 } & & rms (secs) & erh (km) & erz (km) \\
\hline 1.0 & 9233 & $0.34 \pm 0.2$ & $4.6 \pm 8.6$ & $6.9 \pm 10.0$ \\
\hline 0.5 & 9233 & $0.32 \pm 0.2$ & $4.2 \pm 7.6$ & $6.5 \pm 9.0$ \\
\hline 0.0 & 8294 & $0.28 \pm 0.2$ & $3.6 \pm 5.3$ & $5.8 \pm 6.8$ \\
\hline
\end{tabular}

Among all Hypoinverse runs, the one that resulted in the minimum mean rms, erh and erz values of the relocated events was the one that encountered the PAT 1D velocity model and only P-wave phases. More detailed statistics on this relocated catalogue are presented in Table 4.

\section{Table 4 - Statistics on the preferred catalogue with relocated hypocenters of earthquakes in western Greece}

\begin{tabular}{|c|c|}
\hline Statistical Parameter & $\begin{array}{c}\text { Mean value } \pm \text { 1 standard de- } \\
\text { viation }\end{array}$ \\
\hline Number of available phases & $13 \pm 10$ \\
\hline Number of phases used in relocation & $8 \pm 6$ \\
\hline Maximum azimuthal gap $\left(^{\circ}\right)$ & $171 \pm 61$ \\
\hline Distance to nearest station $(\mathrm{km})$ & $40 \pm 35$ \\
\hline Depth $(\mathrm{km})$ & $14.0 \pm 3.9$ \\
\hline RMS travel time residual $(\mathrm{sec})$ & $0.28 \pm 0.2$ \\
\hline Horizontal error $(\mathrm{km})$ & $3.6 \pm 5.3$ \\
\hline Vertical error $(\mathrm{km})$ & $5.8 \pm 6.8$ \\
\hline
\end{tabular}

In Figure 4, we compare the horizontal distribution of epicentres of this catalogue with rms $\leq 0.5$ secs to the corresponding picture prior the relocation. Figure 4a shows the two pictures for the central part of the study area, while in Figure $4 \mathrm{~b}$ analogue comparisons for smaller areas (marked by frames in Fig. 4a) are shown. Relocations illuminate the prevailing, NNE-SSW trending seismogenic structures, e.g. the Cephalonia-Lefkada transform fault, running along the west coast 

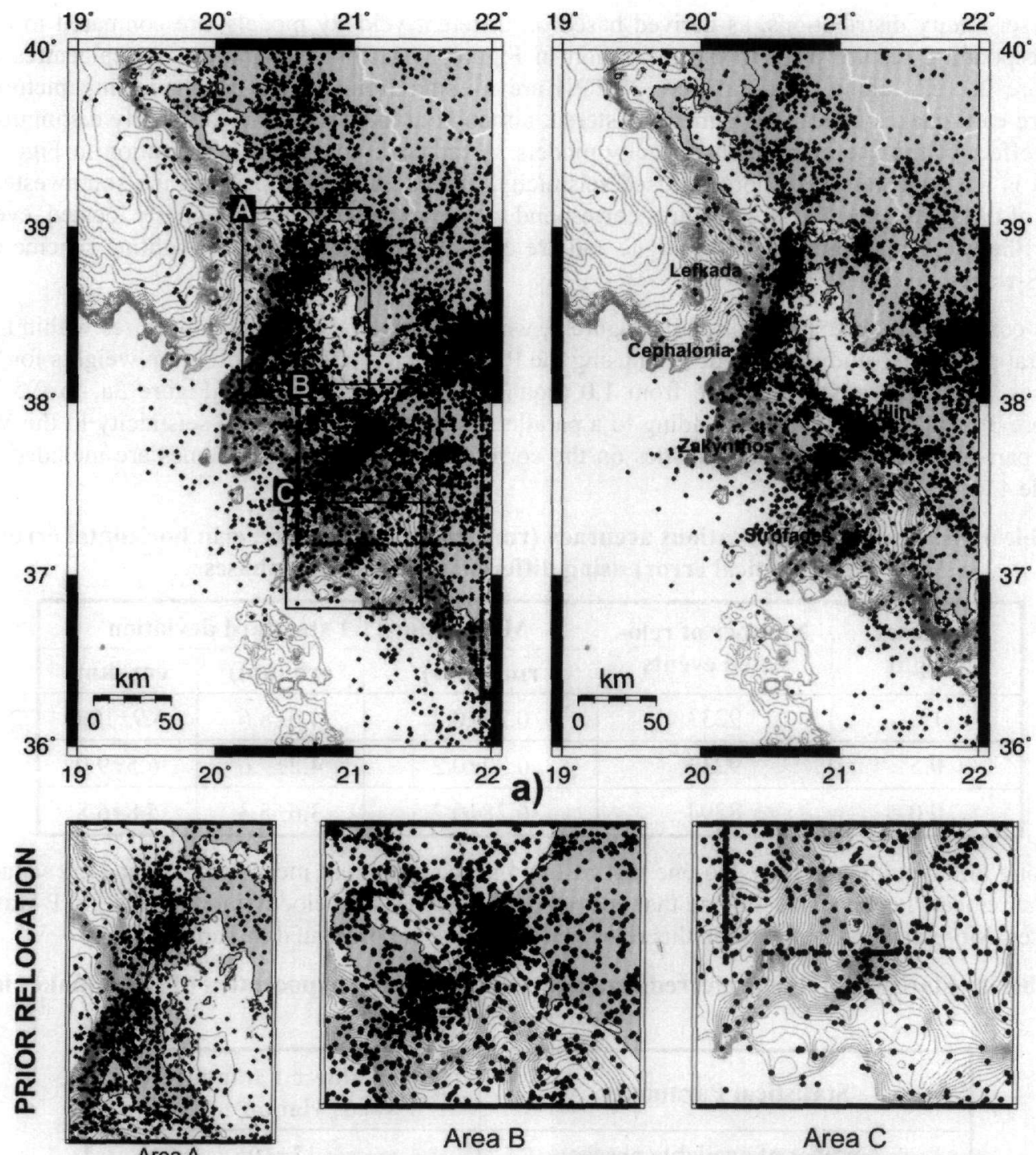

Area B
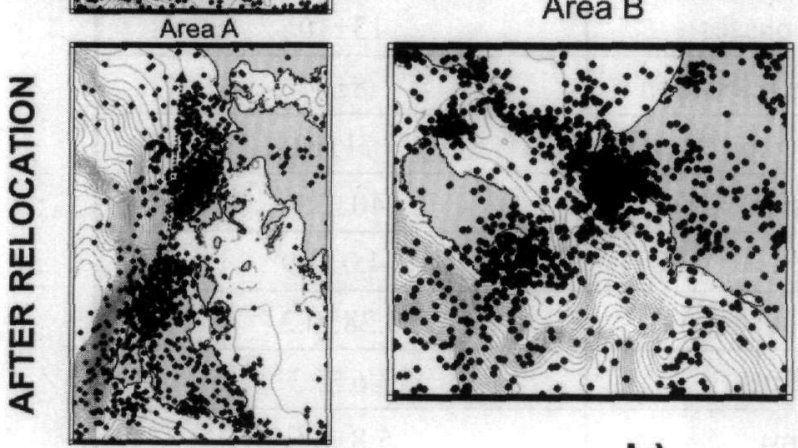

Area C

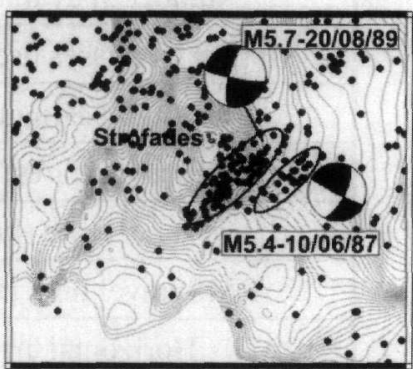

b)

Figure 4 - Comparison of seismicity distributions prior and after the relocation: a) central part of the study area; left and right panels show seismicity prior and after relocation, respectively. Frames in the left panel mark the areas plotted in Figure $4 \mathrm{~b}$. b) enlarged views of the areas A, B and C (from left to right) marked in Figure 4a, prior (top) and after (bottom) relocation 
of the islands. It is evident that most of the seismicity that occurred during the years $2000-2005$ is related to the well-known large structures of the area. However, in fewer cases, relocated epicentres reveal the presence of conjugate structures as for example in the area to the west of Killini (see also the central part of Figure $4 \mathrm{~b}$ ) and within the gulf of Patras, confirming previous studies which suggest active strike-slip faulting of such orientation in the area (e.g. Papazachos et al. 1998, Kiratzi and Louvari 2003, Roumelioti et al. 2004).

An interesting observation in the area of Lefkada (Area A in Fig. 4b) is that, after the relocation, epicentres clustered on the island show the same alignment with that of the epicentres observed offshore NW Cephalonia. The direction of this alignment is also parallel to the principal direction of the west coast of the two islands. The two groups of earthquakes appear to belong to the same structure, which according to Louvari et al. (1999) is the Lefkada segment of the Cephalonia transform fault. The southern termination of the Lefkada segment is accurately marked by the southwestern end of the cluster observed offshore NW Cephalonia. However, to the NW of Lefkada, probably where the Lefkada segment terminates, seismicity appears to be more diffused although a significant part of it is observed along a more northerly (N-S) direction. Finally, it must be noted that we are not certain whether the "gap" observed between S. Lefkada and N. Cephalonia is a constant characteristic of the seismicity picture of the area or whether it is an influence of the aftershock distribution of the 18 August 2003, M6.3 Lefkada earthquake (Karakostas et al. 2004, Zahradnik et al. 2005). Inclusion of data from years before 2000 in the future continuation of our work may clarify this uncertainty.

Relocated epicentres also separate the aseismic areas in an explicit manner. Perhaps the most striking example is the submarine area to the east of Cephalonia Fig. $4 \mathrm{a}$ ), which extends $\sim 50 \mathrm{~km}$ in the E-W direction and appears almost completely free of seismic epicentres. Another characteristic example of such case is presented in Figure $4 \mathrm{~b}$ (Area B) and concerns the NW-SE submarine valley between Killini peninsula and Zakynthos Island. Prior to the relocation, epicentres of the west Peloponnese seismicity appear merged with those observed to the south of Zakythos. However, after using the joint phase catalogue, the two groups of earthquakes are more clearly separated along the Killini - Zakythos valley, i.e. an area almost entirely free of earthquake epicentres.

In the right part of Figure $4 \mathrm{~b}$, we present one of the most striking examples of structure illumination after the re-determination of location parameters. The depicted area (Area $\mathrm{C}$ ) is the area of the small islands of Strofades located to the SE of Zakythos. The NE-SW trending structure, which is obscurely observed in the initial seismicity picture, is clearly outlined after the relocation. This zone may be associated to strike-slip faulting mechanisms that have been reported for this area in the past (Kiratzi and Louvari 2003; Fig. 4b). Furthermore, a secondary, sub-parallel structure is revealed, to the immediate SE of the larger structure. Such improvements are observed throughout the entire study area.

\section{Conclusions}

Routine phase catalogues of the three largest seismological networks in Greece are merged toward the compilation of a joint seismicity catalogue for western Greece. Results of the merging procedure for data covering the years 2000-2005, confirmed that none of the individual catalogues can be considered as a subset of another. Overall, the number of earthquakes after the combination of phase data sets increased by more than $30 \%$ compared to the numbers reported by individual institutes. The compiled joint catalogue includes 9777 events, although 544 of them are assigned less than four phases and thus cannot be relocated.

Joint phases were passed to the Hypoinverse location algorithm and a series of relocation schemes were tested. More specifically, we tested the relative performance of three $1 \mathrm{D}$ velocity models used for routine epicentre determination in Greek seismological institutes, as well as three S-phase weighting schemes (S-phase weights of 1.0, 0.5 and 0.0). Minimum mean rms, erh and erz values 
are $0.28 \mathrm{sec}, 3.6 \mathrm{~km}$ and $5.8 \mathrm{~km}$, respectively and result from the use of the PAT velocity model (use by the Seismological Station of the University of Patras for routine location determinations) and P-phases solely. Incorporating S-phases in Hypoinverse results in slightly improved relocations of already well-determined events, but also inserts a large number (939) of earthquakes which remain poorly located even after the relocation procedure. These bad locations/relocations are explicitly due to the small number of available phases (all these events have less than four reported P-phases) and appear to be diffused to the W-SW part of the study area.

Relocated epicentres provide an enhanced picture of the seismicity of western Greece as they appear more clustered along and around the seismogenic structures of the area. Known seismogenic structures are better outlined and obscure ones are illuminated throughout the area of interest.

The results presented herein are preliminary as there is an on-going effort to extrapolate the merging procedure to years before 2000. Therefore, the joint catalogue can be considered as an "open document", which is continuously updated. Furthermore, it must be noted that so far the suggested procedure applies only to the unification of earthquake phases and not to their magnitudes. However, such improvements will be pursued in the near future.

\section{Acknowledgments}

This work was financially supported by the EU project PREVIEW (www.preview-risk.com). We thank the director of the Institute of Geodynamics of the National Observatory of Athens, Dr. G. Stavrakakis and the director of the Seismological Station of the University of Patras, Prof. G. Tselentis for providing access to the earthquake phase data. Online availability of corresponding data from the Department of Geophysics of the Aristotle University of Thessaloniki facilitated our work significantly. Most of the figures were produced using the GMT software (Wessel and Smith, 1998).

\section{References}

Karakostas, V.G., Papadimitriou, E.E., and Papazachos, C.B., 2004. Properties of the 2003 Lefkada, Ionian Islands, Greece, earthquake seismic sequence and seismicity triggering, Bull. Seism. Soc. Am., 94( 5), $1976-1981$.

Kiratzi, A., and Louvari, E., 2003. Focal mechanisms of shallow earthquakes in the Aegean Sea and the surrounding lands determined by waveform modeling: a new database, Journal of Geodynamics, 36, 251 - 274.

Klein, F.W., 2002. User's Guide to HYPOINVERSE-2000, a Fortran program to solve for earthquake locations and magnitudes, Open File Report 02-171, U.S. Geological Survey.

Lee, W.H.K., and Lahr, J.C., 1972. HYPO71: A computer program for determining hypocenter, magnitude, and first motion pattern of local earthquakes, U.S. Geological Survey OpenFile Report.

Louvari, E., Kiratzi, A.A., and Papazachos, B.C., 1999. The Cephalonia transform fault and its extension to western Lefkada island (Greece), Tectonophysics, 308, 223-236.

Papazachos, B.C., Papadimitriou, E.E., Kiratzi, A.A., Papazachos, C.B., and Louvari E.K., 1998. Fault plane solutions in the Aegean Sea and the surrounding area and their tectonic implication, Bolletino di Geofisica Teorica ed Applicata, 39, 199-218.

Roumelioti, Z., Benetatos, Ch, Kiratzi, A., Stavrakakis, G., and Melis, N., 2004. Evidence for sinistral strike-slip faulting in western Peloponnese (Greece): A study of the 2 December 2002 (M5.5) Vartholomio earthquake sequence, Tectonophysics, 387, 65 - 79. 
Skarlatoudis, A., 2002. Relocation of hypocentral earthquake parameters in Greece with the use of data from local experiments and effects in the strong motion attenuation relations, $M S c$ Thesis, Aristotle University of Thessaloniki, 120pp.

Wessel, P., and Smith, W.H.F., 1998. New improved version of the Generic Mapping Tools released, EOS Trans. $A G U$ 79, 579.

Zahradník, J., Serpetsidaki, A. Sokos, E., and Tselentis, G.-A., 2005. Iterative deconvolution of regional waveforms and a double-event interpretation of the 2003 Lefkada earthquake, Greece, Bull. Seism. Soc. Am., 95, No. 1, 159 - 172, doi:10.1785/0120040035. 